\title{
ACOMPANHAMENTO AO ESTUDANTE À DISTÂNCIA: CURSO "INICIANDO UM PEQUENO GRANDE NEGÓCIO - IPGN", UMA EXPERIÊNCIA DE CAPACITAÇÃO EM LARGA ESCALA
}

\author{
(DISTANCE EDUCATION STUDENT ACCOMPANIMENT: IPGN COURSE, AN EXPERIENCE IN \\ LARGE SCALE CAPACITATION)
}

Sônia Inez Grüdtner Floriano

Giovana Schuelter

Mônica Guarezi Rodrigues

Rita de Cássia Menegaz Guarezi

Universidade Federal de Santa Catarina - UFSC (Brasil)

Márcia Maria Mattos

Serviço Brasileiro de Apoio às Micro e Pequenas Empresas (Brasil)

\section{RESUMO}

Uma das maiores dificuldades encontradas pelas instituições provedoras de cursos na modalidade de educação à distância, desde seu início até os dias atuais, é acompanhar o desenvolvimento de seus estudantes. Atualmente muitas são as possibilidades trazidas pelas novas tecnologias de comunicação e informação, porém é sabido que as mesmas são apenas um meio, pois o diferencial está exatamente na proposta pedagógica do curso. Partindo deste princípio, este artigo pretende apresentar a proposta pedagógica, a metodologia e os recursos tecnológicos utilizados para acompanhar, orientar e apoiar de forma sistemática, permanente e pró-ativa os estudantes de um curso e-learning de larga escala, gratuito com duração de dois meses e carga horária equivalente a trinta horas/aula. Fruto de uma parceria entre o SEBRAE (Serviço Brasileiro de Apoio às Micro e Pequenas Empresas) e o IEA (Instituto de Estudos Avançados). Este curso iniciou em 2001 e até o momento já capacitou 216.648 estudantes.

\begin{abstract}
One of the most difficulties found by the providers institutions of courses on the distance education modality, since its beginning until nowadays, is to accompany the development of its students. Today there are too much possibilities brought up by the new technologies of communication and information. Although it is known that those one are only a thru, once the difference is exactly in the pedagogical proposal of the course. For this, this paper intens to present the pedagogical proposal, the methodology and the technological resourles utilized to accompany, orient and support on de systematic way,
\end{abstract}


Sonia Grüdtner, Giovana Schuelter, Mónica Guarezi, Rita Menegaz y Marcia Matos ACOMPAHAMENTO AO ESTUDANTE A DISTANCIA: CURSO “INICIANDO UM PEQUEÑO GRANDE NEGOCIO- IPGN", UMA EXPERIENCIA DE CAPACITAÇAO EM LARGA ESCALA

permanent and proactive the students of a e-learning course of large scale, free with two months lenght, and 30 hours/class charge. It is a result of a partnership between SEBRAE (Serviço Brasileiro de Micro e Pequenas Empresas) and IEA(Instituto de Estudos Avançados). This course has begun in 2001 and til the present moment has capacited 216.648 students.

\section{INTRODUÇÃO}

A gênese da Educação à Distância - EaD traz posicionamentos diferenciados. Alguns autores estabelecem o século XVIII como marco inicial da EaD. Outros defendem que um dos primeiros registros de ações de EaD é na Inglaterra, por volta de 1840 onde o processo comunicativo entre a instituição e os estudantes ocorria por meio do sistema de taquigrafia e correio postal. No Brasil, as primeiras ações registradas são datadas cem anos mais tarde, por volta de 1940, com cursos técnicos profissionalizantes oferecidos pelo Instituto Universal Brasileiro com o processo comunicativo baseado em informações transmitidas por meio de programas radiofônicos.

Desde o início, um dos maiores desafios a ser vencido por todas as instituições, independentemente do nível e natureza dos cursos, é estabelecer um processo comunicativo mediatizado que favorecesse vínculos, de forma a transpor a barreira da distância espacial, temporal e o sentimento de solidão, estimulando, o processo ensino-aprendizagem colaborativo.

Sabe-se que estruturar um processo comunicativo multidirecional que estimule a interação entre os envolvidos, não é uma tarefa fácil. Exige muito mais que estruturas tecnológicas de ponta, pois as tecnologias são apenas meio. Porém, são eficazes se usadas adequadamente com base em uma proposta pedagógica que priorize um aprendizado dinâmico, ativo, colaborativo e com interações. Juntamente com a proposta pedagógica adequada é necessário que a instituição tenha uma equipe de profissionais capacitados, trabalhando de forma integrada e colaborativa.

Nesse sentido, a autora Belloni (1999) afirma que as instituições devem substituir a noção de professor de uma entidade individual em uma entidade coletiva, o que ela prefere denominar de professor coletivo. A autora salienta que no ensino convencional o professor é responsável individualmente pelo processo ensinoaprendizagem juntamente ao estudante, já na $\mathrm{EaD}$ a responsabilidade passa ser de uma equipe de especialistas em: conteúdos, especialistas em educação e em $\mathrm{EaD}$, produção de materiais, tutores, monitores e avaliadores. 
Sonia Grüdtner, Giovana Schuelter, Mónica Guarezi, Rita Menegaz y Marcia Matos ACOMPAHAMENTO AO ESTUDANTE A DISTANCIA: CURSO "INICIANDO UM PEQUEÑO GRANDE NEGOCIO- IPGN", UMA EXPERIENCIA DE CAPACITAÇAO EM LARGA ESCALA

Corroborando com Belloni, o autor Prieto (1985), enfatiza que para se realizar um trabalho com qualidade, a equipe docente deve manter relações democráticas entre todos os seus integrantes. A comunicação deve ser a base de todo o processo e, por isso, deve ser permanente, quer dizer, as decisões devem ser partilhadas, com objetivos comuns claros, permeado por avaliação durante todo o transcorrer do processo. Deve haver divisão de tarefas, porém cada um deve conhecer o trabalho do outro.

Guarezi (2004) compartilha do mesmo ponto de vista dos autores e afirma que em cursos à distância devem participar agentes das áreas pedagógica, tecnológica e administrativa. E que todos os integrantes que se envolvam em um curso à distância devem ter conhecimentos sobre $\mathrm{EaD}$, pois esses conhecimentos contribuirão tanto com a realização dos trabalhos, como facilitarão as inter-relações entre eles, dando aos envolvidos a visão geral dos processos e procedimentos.

A autora reforça ainda que, mesmo a instituição tendo uma equipe com conhecimentos consolidados na área de $\mathrm{EaD}$, deve se retro-alimentar permanente, por meio de pesquisa, cursos, participação em congressos e estudos organizados pela própria equipe. Segundo ela, os estudos internos podem, inclusive ser um meio de fortalecer as possibilidades de gestão do conhecimento dentro da equipe.

A partir do que foi exposto, a seguir será focado a discussão de pontos-chave que influenciam diretamente no processo de acompanhamento ao estudante à distância.

\section{ACOMPANHAR É PRECISO}

Por muito tempo as instituições provedoras de EaD estruturavam seus cursos considerando que por ter uma clientela adulta o estudo deveria ser auto-dirigido, tendo como fator-chave materiais auto-instrucionais com poucas possibilidades de interlocução entre estudantes e instituição. Porém, alguns autores afirmam que nenhum ato de aprender é completamente auto-dirigido, de forma que o estudante seja tão autoconfiante a ponto de excluir todas as fontes externas ou estímulos. (BROOKFIELD, 1986).

Como afirma (Brockett e Hiemstra, 1991), adultos têm graus variados de vontade e habilidade para assumir responsabilidade pessoal por aprender. Pode haver tipos de personalidades que venham a dificultar a auto-direção, ou então, indivíduos que por alguma razão não desenvolveram essa capacidade. (HARRIS, 1989). 
Sonia Grüdtner, Giovana Schuelter, Mónica Guarezi, Rita Menegaz y Marcia Matos ACOMPAHAMENTO AO ESTUDANTE A DISTANCIA: CURSO “INICIANDO UM PEQUEÑO GRANDE NEGOCIO- IPGN", UMA EXPERIENCIA DE CAPACITAÇAO EM LARGA ESCALA

Assim sendo, se tratando de estudantes adultos, a responsabilidade por adquirir conhecimento deve partir da próxima vontade e necessidade, porém deve ocorrer com a orientação e apoio de outros. Isso se deve ao fato de que os indivíduos adultos são formados de forma diretiva, onde o professor via de regra direciona o processo ensino-aprendizado. Dessa forma, a habilidade de autodisciplina e autonomia para os estudos em lugar de ser regra na sociedade contemporânea brasileira é uma exceção. Sweet (1991) e Brookfield (1986) já salientavam que os indivíduos adultos podem possuir autonomia em compromissos profissionais, familiares e pessoais, mas com o processo de estudo é raro.

Sem perceber a importância de ter habilidade de autonomia, a maioria dos estudantesingressa em cursos na modalidadeà distância sem saber seestãopreparados para este novo ambiente de aprendizagem e acabam apresentando dificuldades. Estas dificuldades podem ser agrupadas em dois blocos: necessidades e dificuldades de cunho pessoal e com a instituição ao qual está estudando. As dificuldades de cunho pessoal estão relacionadas à gestão de tempo, ao planejamento e à autodisciplina para o estudo, pressupostos essenciais para o processo de estudo a distância. E as dificuldades com a instituição estão associadas ao tratamento impessoal; material mal elaborado; falta de orientação para ter certeza de que está no caminho certo; ausência dos colegas para trocar idéias e pareceres sobre diversos temas e saber se outros companheiros estão na mesma situação, se estão em dificuldades ou em situação parecida para socializarem possíveis soluções. Tal situação tende a se agravar levando o estudante ao desânimo, à sensação de incapacidade e à evasão. (PAUL,1999:33,50, LANDIM,1997: 125).

Gutierrez, em 1994, preocupado com aspectos como esses mencionados acima já afirmava que o acompanhamento aos estudantes era um dos maiores dramas da $\mathrm{EaD}$, pois a maioria das instituições não conseguiam personalizar a interação e manter comunicação constante entre e com os estudantes. Partindo da afirmação do autor o que se tem de concreto é que, dependendo do projeto pedagógico adotado, a instituição opta apenas por ações de atendimento, apoio e orientação de forma reativa (o estudante solicita apoio e orientação à instituição). Ou por uma concepção mais ampla, pró-ativa, por meio de um acompanhamento de todo o percurso do estudante no curso.

Guarezi (2000) também preocupada com os mesmos aspectos até o momento apresentado enfatiza que a modalidade à distância exige dos estudantes uma cultura do processo de ensino-aprendizagem diferente da existente modalidade presencial. Diante disso, a autora chama a atenção sobre a importância da preparação 
Sonia Grüdtner, Giovana Schuelter, Mónica Guarezi, Rita Menegaz y Marcia Matos ACOMPAHAMENTO AO ESTUDANTE A DISTANCIA: CURSO “INICIANDO UM PEQUEÑO GRANDE NEGOCIO- IPGN", UMA EXPERIENCIA DE CAPACITAÇAO EM LARGA ESCALA

permanente de todos os envolvidos como um aspecto fundamental a ser definido na proposta pedagógica de qualquer curso na modalidade à distância.

Acompanhar o percurso do estudante significa: saber como ele estuda, que dificuldades apresenta quando busca orientação, se relaciona com os colegas para estudar, se consulta bibliografias de apoio, se realiza as tarefas e exercícios propostos, se é capaz de relacionar teoria/prática. (NEDER, 2000).

O acompanhamento ao estudante à distância, é essencial, é a base, é a sustentação de qualquer ação de apoio e orientação, pois é a única forma que a instituição tem para conhecer as reais necessidades e suas características de seus egressos. (FLORIANO, 2002).

A autora enfatiza que para se acompanhar os estudantes com eficiência e eficácia, alguns aspectos devem ser considerados, tais como: se ter uma proposta clara do que se quer que o estudante aprenda; quais as competências o mesmo deverá desenvolver; o que ele já sabe sobre o assunto a ser tratado; quais são as principais necessidades e dificuldades e outros. Para obter tais informações, o acompanhamento do processo ensino-aprendizagem deve ser permanente, sistemático e estimular o diálogo e a interação entre todos os atores. E para que isso ocorra deve haver esforço coletivo de vários agentes de forma integrada. (FLORIANO, 2002).

Para acompanhar o processo ensino-aprendizagem dos estudantes é necessário que a instituição estruture uma equipe de profissionais responsáveis pelo acompanhamento indireto e direto. Os profissionais que atuam no acompanhamento indireto são aqueles que trabalham nos "bastidores" desde o planejamento do curso para uma determinada clientela, passando pela elaboração de todos os materiais didático-pedagógicos, pelo planejamento das aulas, pelo constante processo avaliativo e pela proposta de novas ações, a partir dos feedbacks constantes, analisados por meio do acompanhamento. E os responsáveis pelo acompanhamento direto, são aqueles que acompanham os estudantes desde início do curso até a conclusão. Estes atores podem ser representados por professores da própria disciplina, tutores e monitores, que deverão estar constantemente propondo melhorias no processo. A escolha destes agentes dependerá das especificidades do curso e do desenho educacional do mesmo. Sendo assim, pode haver tutores e monitores ou professores e monitores.

Os atores responsáveis pelo acompanhamento direto devem, segundo Aretio (1994), Landim (1997), Gomes (2000), Floriano (2002) ter três funções principais: orientadora - ligada diretamente aos aspectos afetivos, às atitudes e emoções; 
Sonia Grüdtner, Giovana Schuelter, Mónica Guarezi, Rita Menegaz y Marcia Matos ACOMPAHAMENTO AO ESTUDANTE A DISTANCIA: CURSO "INICIANDO UM PEQUEÑO GRANDE NEGOCIO- IPGN", UMA EXPERIENCIA DE CAPACITAÇAO EM LARGA ESCALA

investigativa - refere-se ao tutor/monitor como pesquisador, aquele que revê procedimentos, estuda situações, averigua as dificuldades, registra e propõe mudanças e colaborativa - relacionada com o atendimento técnico-administrativo.

\section{A INTERAÇÃO É PRIMORDIAL}

Diante do que foi exposto anteriormente, enfatiza-se que sem interação não há processo de aprendizagem, assim como, sem comunicação não há como conhecer as necessidades e expectativas dos estudantes. Entende-se por interação um processo comunicativo centrado em uma relação dialógica, horizontal entre os pares envolvidos (FREIRE, 1987) e a interatividade destes com os objetos de conhecimento.

Cabe aqui ressaltar que interação, no conceito sociológico, é a ação recíproca entre dois ou mais atores onde ocorre intersubjetividade, isto é, o encontro de dois sujeitos - que pode ser direta ou indireta (mediatizada por alguma tecnologia); já o termo interatividade, é usado para designar a atividade humana, do usuário, de agir e receber uma retro alimentação (CD ROM de consulta, hipertextos em geral, ou jogos informatizados) de uma máquina. (BELLONI, 1999).

O processo interativo mediatizado propiciado pelas tecnologias interativas síncronas e assíncronas (chat, e-mail, listas de discussões, comunidades de práticas), e as possibilidades de ações pautadas na interatividade (jogos interativos, simuladores) advindas da $4^{\mathrm{a}}$ e $5^{\mathrm{a}}$ geração tecnológica da EaD, estão revolucionando o conceito de distância e de possibilidades de comunicação. Tanto a possibilidade de interação como de interatividade, pautadas em uma proposta pedagógica adequada, estão revolucionando o processo ensino-aprendizagem. Estudar à distância não significa mais estudo individualizado e solitário. $\mathrm{O}$ aspecto essencial não é mais a distância física, e sim, um redimensionamento espaço ${ }^{1}$ temporal $^{2}$ no processo ensino-aprendizagem.

Enfim, com a crescente utilização destas tecnologias, a EaD está perdendo suas características iniciais que estavam pautadas na separação física entre estudantes e instituição, pois está rompendo com a relação de tempo/espaço que constitui a escola que se conhece. Assim, o termo "distância" deve ser repensado, uma vez que não significa puramente distância física e geográfica. Cada vez mais a $\mathrm{EaD}$ busca reduzir ou eliminar as distâncias, não se intimida mais com elas, nem lhe é submissa. O próprio termo "EaD" deve ser repensado, para talvez simplesmente "educação não presencial”. (ALONSO, 2000). Shale em 1990 já afirmava que com a crescente 
Sonia Grüdtner, Giovana Schuelter, Mónica Guarezi, Rita Menegaz y Marcia Matos ACOMPAHAMENTO AO ESTUDANTE A DISTANCIA: CURSO “INICIANDO UM PEQUEÑO GRANDE NEGOCIO- IPGN", UMA EXPERIENCIA DE CAPACITAÇAO EM LARGA ESCALA

possibilidade de interação a distância é muito mais retórica do que um problema real para a organização de novos processos educativos.

Como foi apresentado acima, temos disponíveis uma grande variedade de tecnologias de comunicação e informação que facilitam a comunicação. Porém nos deparamos com dois principais aspectos que merecem ser observados: A restrição de acesso em países em desenvolvimento como o Brasil e as estratégias adequadas de utilização. No entanto, o acesso a tecnologia também não garante a eficácia e eficiência da comunicação. Para que haja um processo comunicativo adequado não basta ter acesso as tecnologias, tem de haver uma clara definição do que é comunicação e como deve ocorrer o processo comunicativo mediatizado que estimule o compartilhamento de informações e construção do conhecimento. Tendo clareza destes aspectos, será possível delinear estratégias de comunicação entre estudantes e entre estudantes e agentes responsáveis diretos pelo acompanhamento, apoio e atendimento. Após esta explanação, será apresentado a experiência com um curso de capacitação de larga escala realizado totalmente por internet.

\section{CURSO IPGN, UMA EXPERIÊNCIA DE CAPACITAÇÃO EM LARGA ESCALA}

O curso é fruto da parceria do SEBRAE (www.sebrae.com.br) com o Instituto de Estudos Avançados - IEA (www.iea.org.br). Estas duas instituições desenvolveram conjuntamente o ambiente educacional e de gestão; as estratégias pedagógicas, a transposição do conteúdo e as dinâmicas de aprendizagem.

Uma das premissas consideradas no planejamento do curso IPGN foi a de atender a um grande número de pessoas, com qualidade. Não se pretendia simplesmente oferecer um curso para um grande contingente populacional, mas, sobretudo, propiciar um ambiente de interações que facilitasse aos participantes a elaboração, re-elaboração e construção de novos conhecimentos.

Oferecido gratuitamente em larga escala a todos os estados da federação, desde de 2001, o IPGN foi desenhado para atender uma clientela com escolaridade a partir do ensino médio incompleto e com conhecimento básico de computação e navegação em Internet. Porém, hoje, atende aos diferentes níveis de ensino, inclusive estudantes universitários. 
Sonia Grüdtner, Giovana Schuelter, Mónica Guarezi, Rita Menegaz y Marcia Matos ACOMPAHAMENTO AO ESTUDANTE A DISTANCIA: CURSO "INICIANDO UM PEQUEÑO GRANDE NEGOCIO- IPGN", UMA EXPERIENCIA DE CAPACITAÇAO EM LARGA ESCALA

Até o momento, são 216.648 participantes. O índice de conclusão do curso é significativo, pois apresenta uma taxa média de conclusão de $66,38 \%$. A cada ano, 70 mil novos estudantes são atendidos pelo curso, divididos em turmas de 200 estudantes cada uma. O IPGN é atualmente o maior programa aberto, gratuito, de formação empreendedora via Internet de toda a América Latina.

Contando com uma carga-horária equivalente a 30 horas, com período para realização de dois meses, o curso objetiva instrumentalizar os participantes para o planejamento de um novo empreendimento e fazê-los refletir sobre sua capacidade empreendedora. É composto por cinco módulos: Perfil Empreendedor, Identificando Oportunidades de Negócios, Análise de Mercado, Concepção dos Produtos e Serviços e Análise Financeira. Além da elaboração de um plano de negócios que permeia os 5 módulos.

Desde sua implantação, em 2001, o curso passou por constantes modificações, visando ao seu aperfeiçoamento. As pesquisas de satisfação e de impacto, bem como, os estudos e a aplicação de novos recursos, processos e metodologias contribuíram para a eficácia da aprendizagem. Pode-se confirmar tal afirmativa nos dados a seguir.

Entre os participantes concluintes, o trabalho de tutoria é avaliado por $80,20 \%$ como excelente e por 18,86\% como bom. O conteúdo é considerado excelente por 79,78\% e bom por 19,53\%. (Pesquisa de Satisfação Interna, 2005) ${ }^{3}$. Quase a totalidade dos estudantes (99,30\%), após participar do IPGN, manifesta interesse em participar de outros cursos do SEBRAE via Internet. (Pesquisa de Satisfação Interna, 2005).

Foi o compromisso com a qualidade, com que o SEBRAE e o IEA conduziram suas ações e a seriedade com que defendem os processos educacionais, que levou o IPGN a ganhar da Associação Brasileira de Educação a Distância - ABED em 2004, o "Prêmio de Excelência ABED / Embratel". A ABED premia anualmente os melhores casos de sucesso de educação à distância do Brasil.

O IPGN confirma-se, assim, como referência para outras iniciativas em Educação à Distância - EaD no SEBRAE, no IEA e certamente para outras instituições brasileiras. 
Sonia Grüdtner, Giovana Schuelter, Mónica Guarezi, Rita Menegaz y Marcia Matos ACOMPAHAMENTO AO ESTUDANTE A DISTANCIA: CURSO “INICIANDO UM PEQUEÑO GRANDE NEGOCIO- IPGN", UMA EXPERIENCIA DE CAPACITAÇAO EM LARGA ESCALA

\section{A proposta educacional do curso IPGN}

A proposta educacional é pautada no referencial educacional do SEBRAE que considera o indivíduo em todas as suas dimensões. O foco principal é o aprendiz empreendedor em seus múltiplos aspectos: cognitivo, de habilidade e atitudinal. Esta visão educacional pauta-se nos quatros pilares defendidos pela UNESCO para a Educação do Século XXI: aprender a conhecer, aprender a fazer, aprender a conviver e aprender a ser, publicadas por Jacques Delors (2000). A leitura dos pilares e sua aplicação se baseia nos princípios das teorias de aprendizagem Cognitivista, Humanista e Sociocrítica.

Da teoria cognitivista busca-se os princípios sobre o funcionamento da mente, as formas utilizadas pelo ser humano para aprender, e demonstrar essa aprendizagem, de maneira a modificar e aperfeiçoar seus processos cognitivos.

Da teoria humanista são observados os princípios que tornam a aprendizagem significativa e que permitem ao indivíduo aprofundar seu processo de autoconhecimento e, assim, conviver de forma mais harmônica consigo mesmo e com os diferentes grupos. Mediante princípios dessa concepção, o indivíduo é estimulado a desenvolver seu potencial criativo, ampliando as chances de alcançar êxito em seus empreendimentos.

A teoria sociocrítica orienta que a educação é um processo social, político e econômico global, fundado em valores sociais. Consequentemente, os conteúdos dos cursos devem ser contextualizados, garantindo como resultado um processo transformador, não só no âmbito da pessoa, mas também da sociedade.

As dimensões aprender a conviver e aprender a ser apresentam-se integradas nas atitudes, pois, acredita-se que relacionar-se é elemento fundamental para a constituição da identidade pessoal e coletiva e para o sucesso de qualquer ação empreendedora.

A orientação propiciada para o desenvolvimento do SER está relacionada ao desenvolvimento integral do ser humano e inclui múltiplos aspectos da personalidade que vão desde a riqueza e complexidade do processo de autoconhecimento aos modos de agir baseados em valores, ideais e metas de vida pessoais, profissionais e sociais. Desenvolver a consciência individual e social representa uma convergência entre a unidade e a diversidade, na medida em que se trata de fortalecer a reflexão, a metacognição, ao tempo de buscar sentido nas metas sociais e de auto-realização. 
Sonia Grüdtner, Giovana Schuelter, Mónica Guarezi, Rita Menegaz y Marcia Matos ACOMPAHAMENTO AO ESTUDANTE A DISTANCIA: CURSO "INICIANDO UM PEQUEÑO GRANDE NEGOCIO- IPGN", UMA EXPERIENCIA DE CAPACITAÇAO EM LARGA ESCALA

Na dimensão aprender a conhecer, o objetivo pedagógico é o desenvolvimento do pensamento superior reflexivo e crítico, com uma atitude de investigação e de organização do conhecimento, ou seja, aprender a conhecer e a pensar.

Na dimensão aprender a ser/conviver, o objetivo educacional é estimular o conhecimento e o desenvolvimento das potencialidades individuais - cognitivas, de ser pessoa, de conviver e, principalmente, de ser criativo - por meio do autoconhecimento e da capacidade de interação com o grupo.

Na dimensão aprender a fazer, o objetivo é estimular a transformação da teoria em ação, isto é, a aplicação do conhecimento em uma prática refletida e planejada. Trata-se de educar para o êxito. Envolve o processo de atendimento às necessidades individuais e do empreendimento, por meio do trabalho, não só como fator de sobrevivência e de auto-realização, mas, também, como forma de contribuir para a melhoria da qualidade de vida da sociedade.

A proposta educacional propõe, também, reflexões e orientações para desenvolver estratégias que possibilitam a formação de pessoas capazes de enfrentar problemas, criar e definir soluções e buscar alternativas. Destacam a necessidade de propiciar aos alunos a construção de um conjunto de conhecimentos, ao lado de habilidades e competências que lhes permitam aprender a aprender e buscar novas informações.

Desta forma, o acompanhamento aos alunos no IPGN se destaca e tem uma excelente avaliação dos alunos. $97 \%$ dos alunos apontam trabalho da tutoria como excelente e bom.

\section{O acompanhamento aos alunos}

A proposta pedagógica acima descrita é norteadora de toda a ação dos agentes de acompanhamento aos estudantes do IPGN. Desta forma, o sistema de acompanhamento aos estudantes se constitui no trabalho colaborativo e interrelacionado de vários agentes almejando dois principais objetivos: estimular um processo ensino-aprendizado colaborativo por meio de um processo comunicativo multidirecional e o permanente aprimoramento dos processos.

O SEBRAE e o IEA, tendo clareza da importância de se ter uma equipe de profissionais bem estruturada para oferecer um curso de qualidade, investiu no sistema de acompanhamento ao estudante à distância. O sistema é composto por 
Sonia Grüdtner, Giovana Schuelter, Mónica Guarezi, Rita Menegaz y Marcia Matos

ACOMPAHAMENTO AO ESTUDANTE A DISTANCIA: CURSO "INICIANDO UM PEQUEÑO GRANDE NEGOCIO- IPGN", UMA EXPERIENCIA DE CAPACITAÇAO EM LARGA ESCALA

vários agentes que oferecem atendimento e apoio direto e indireto aos estudantes. No acompanhamento direto têm-se os tutores e o suporte técnico. No acompanhamento indireto conta-se com a equipe de gestão e a tutoria máster.

Cabe à equipe de gestão acompanhar permanentemente o desenvolvimento do curso, atendendo, apoiando e orientando as ações dos demais agentes. A tutoria master, por sua vez, acompanha e presta apoio à equipe de tutoria, faz avaliação de processos e é uma espécie de elo entre os tutores e os coordenadores. Quanto aos agentes diretos destaca-se a função da tutoria. O modelo de gestão de tutoria assumido pelo curso é um dos fatores responsáveis pelo sucesso alcançado. $\mathrm{O}$ tutor acompanha o desempenho de cada estudante segundo um calendário de atividades sugerido, fator essencial para que estes especialistas possam gerenciar turmas de 200 estudantes cada. A partir de indicadores de desempenho individuais o sistema agrupa estudantes com desempenho similar, permitindo que o tutor desencadeie ações de comunicação e incentivo para cada um dos diferentes grupos. Existe ainda um período de tutoria destinado à consolidação dos planos de negócios (PN), realizados pelos estudantes ao longo do curso.

Durante o processo de acompanhamento, são os tutores que estão em constante diálogo, atendendo, apoiando, orientando e acompanhando diariamente de forma personalizada, sistemática e pró-ativa os estudantes. A principal ferramenta de trabalho é o ambiente on-line de onde o tutor obtém todas as informações dos estudantes que estão sob sua responsabilidade. Essas informações são atualizadas permanentemente e estão à disposição do participante 24 horas por dia. As principais ferramentas de comunicação entre tutoria e participantes são: "Tira-dúvidas", $E$ mail, Fórum e Chat em dias agendados.

Para desempenhar a função de tutor do IPGN é necessário possuir as seguintes competências: domínio do conteúdo do curso; domínio do ferramental técnico (incluindo o ambiente educacional); conhecimento de $\mathrm{EaD}$ e compreensão do processo educativo centrado na aprendizagem colaborativa. $\mathrm{O}$ tutor atua como dinamizador para o estudo e incentivador da aprendizagem individual e coletiva. Respondem as dúvidas em relação ao conteúdo e acompanha de forma pró-ativa a evolução dos estudantes. Atua, também, como agente avaliador de processos. A seguir serão descritas as principais atribuições da tutoria. 
Sonia Grüdtner, Giovana Schuelter, Mónica Guarezi, Rita Menegaz y Marcia Matos ACOMPAHAMENTO AO ESTUDANTE A DISTANCIA: CURSO "INICIANDO UM PEQUEÑO GRANDE NEGOCIO- IPGN", UMA EXPERIENCIA DE CAPACITAÇAO EM LARGA ESCALA

\section{a) Atribuições dinamizadoras de estudos}

- Comunicar-se com os alunos em linguagem adequada, no conteúdo e na forma, ao estágio de desenvolvimento de cada um, em relação aos objetivos do curso;

- Utilizar palavras estimulantes e positivas evitando gírias e expressões desqualificadoras;

- Interagir com o grupo mantendo-se presente;

- Valorizar os conhecimentos e experiências trazidas pelos estudantes, estimulando-os no desenvolvimento de novos esquemas mentais (habilidades e atitudes);

- Compartilhar experiências.

- Orientar e ambientar os alunos no curso;

- Acompanhar o desempenho dos alunos em relação ao cronograma oficial do curso;

- Estimular o estudo de temas pertinentes ao curso, buscando a integração especialização/generalização;

- Dialogar e estimular o diálogo permanente entre os estudantes, de forma contextualizada e significativa;

- Ser agente na harmonização de conflitos de forma assertiva;

- Utilizar diferentes estratégias éticas de estímulo à aprendizagem eà conclusão do curso, considerando os diferentes canais de aprendizagem humana (ex: propor situações- problemas; desafios, desencadear e incentivar reflexões, colocar o aprendiz perante questões éticas, sociais, profissionais e até conflitivas, propor experimentos e vivências responsáveis);

- $\quad$ Assumir atitude humilde e confiante;

- $\quad$ Fazer uso das diversas ferramentas de comunicação para manter a motivação da turma;

- Fazer acompanhamento individual, quando necessário;

- Responder as dúvidas e aos e-mails dos alunos no prazo máximo de 24 horas em dias úteis;

- Orientar os alunos, dentro do ambiente do curso quanto aos limites e possibilidades de atividades extra-curso. O SEBRAE não se responsabilizará por atividades realizadas pelos alunos fora do ambiente do curso.

\section{b) Atribuições incentivadoras de aprendizagem individual e coletiva}

- Estabelecer um ambiente propício para o aprendizado individual e colaborativo;

- Promover a participação e a integração entre os alunos na comunidade; 
Sonia Grüdtner, Giovana Schuelter, Mónica Guarezi, Rita Menegaz y Marcia Matos ACOMPAHAMENTO AO ESTUDANTE A DISTANCIA: CURSO “INICIANDO UM PEQUEÑO GRANDE NEGOCIO- IPGN", UMA EXPERIENCIA DE CAPACITAÇAO EM LARGA ESCALA

- Motivar os estudantes estimulando-os a discussão de temas e reforçando o conteúdo do curso;

- Contribuir de forma mediadora ou facilitadora para que os aprendizes superem concepções prévias e construam concepções mais fundamentadas;

- Adotar estratégias que estimulem o autoconhecimento e a auto-estima, bem como, a autocondução;

- $\quad$ Promover chats temáticos;

- Apresentar perguntas orientadoras;

- Ler com atenção todos os e-mails da comunidade, respondendo-os ou estimulando o debate, quando for o caso;

\section{d) Atribuições gerais}

- Participar ativamente da sala de tutores.

- Participar ativamente dos eventos de educação continuada promovidos pelo SEBRAE.

- Realizar as atividades de tutoria no ambiente do curso, acessando-o, necessariamente todos os dias úteis, devendo entrar no ambiente e fazer tutoria, necessariamente, um final de semana no mês, por $2 \mathrm{~h}$ por final de semana, mantendo-se, entretanto, às 1oh semanais previstas no manual do tutor.

Sobre as competências estabelecidas, a excelente atuação da tutoria é comprovada pela pesquisa de satisfação (2005). O domínio do conteúdo pela tutoria foi avaliado entre bom e excelente por $(98,97 \%)$ dos participantes. Para (98,73\%) dos respondentes, a tutoria promoveu um excelente relacionamento entre os participantes. A linguagem utilizada foi considerada entre boa e excelente para $(98,73 \%)$ dos participantes. A tutoria criou um ambiente favorável à participação da turma para (95,26\%) dos participantes.

Além do acompanhamento e apoio direto da tutoria, os estudantes recebem orientação e apoio dos agentes do suporte técnico. Cabe ao suporte técnico o atendimento de dificuldades técnicas relacionadas a utilização do ambiente Internet e $e$-mail. Fica a disposição dos estudantes 12 horas por dia, sete dias na semana. Porém a pesquisa interna de satisfação (2004) demonstra que esses serviços são utilizados por apenas por $32,21 \%$ dos estudantes. De acordo com esses dados é possível concluir que o ambiente Internet é de fácil utilização. 
Sonia Grüdtner, Giovana Schuelter, Mónica Guarezi, Rita Menegaz y Marcia Matos ACOMPAHAMENTO AO ESTUDANTE A DISTANCIA: CURSO "INICIANDO UM PEQUEÑO GRANDE NEGOCIO- IPGN", UMA EXPERIENCIA DE CAPACITAÇAO EM LARGA ESCALA

\section{NOTAS}

1 Abrangência geográfica: alunos estudando juntos simultaneamente de locais completamente diferentes.

2 Acesso rápido ao conhecimento no horário definido pelo aluno.

3 Pesquisa Interna de Satisfação: Este tipo de pesquisa é aplicada no ambiente via Internet, aos alunos no final do curso. O ambiente gera relatórios dinâmicos por turma, todas as turmas, agrupadas por estado, por região, por tutor, por ano etc.

\section{REFERÊNCIAS BIBLIOGRÁFICAS}

Alonso, Kátia M. A educação a distância e um programa institucional de formação de professores em exercício. In: PRETI, Oreste. (org.) Educação a Distância: construindo significados. Cuiabá: NEAD/IE - UFMT; Brasília: Plano, 2000.

Belloni, Maria Luiza. Educação a Distância. Campinas, SP: Autores Associados, 1999.

Gutiérrez, Francisco e Prieto, Daniel. A mediação pedagógica: educação a distância alternativa. Campinas: Papirus. 1994.

Brookfield, S. D. (1986) Understanding and Facilitating Adult Learning. A comprehensive analysis of principles and effective practice, Milton Keynes: Open University Press.

Brockett, R. \& Hiemstra, R. Self-Direction in adult Learning: Perspectives on Theory, Research, and Practice, Routledge, London. 1991.

Christensen, R., Garvin, D., \& Sweet, A. Education for judgment: The artistry of discussion leadership. Harvard Business School Press. Boston . 1991.

Freire, Paulo. Pedagogia do oprimido. 17ed. Rio de Janeiro: Paz e Terra, 1987.
Floriano, Sônia Inez Grüdtner. Proposta de um Sistema de Acompanhamento ao Estudante a Distância. Florianópolis, 2002. Dissertação Mestrado (Programa de Pósgraduação em Engenharia de Produção) Centro Tecnológico - Universidade Federal de Santa Catarina.

Guarezi, Rita de Cássia. Sistema de Gestão Pedagógica: delineando processos e procedimentos para a qualidade em cursos E-Learning. Tese (Programa de PósGraduação em Engenharia de Produção) - Universidade Federal de Santa Catarina. 2004.

Shale, D. R. and Garrison, D. Education at a Distance: From issues to practice. Melbourne, FL.: Krieger. 1990.

SEBRAE/Nacional. Pesquisa Interna de Impacto do Curso Iniciando um Pequeno Grande Negócio. (2004)

SEBRAE/Nacional. Pesquisa Interna de Satisfação do Curso Iniciando um Pequeno Grande Negócio. (2004)

SEBRAE/Nacional. Pesquisa Interna de Satisfação do Curso Iniciando um Pequeno Grande Negócio. (2005) 
Sonia Grüdtner, Giovana Schuelter, Mónica Guarezi, Rita Menegaz y Marcia Matos ACOMPAHAMENTO AO ESTUDANTE A DISTANCIA: CURSO “INICIANDO UM PEQUEÑO GRANDE NEGOCIO- IPGN", UMA EXPERIENCIA DE CAPACITAÇAO EM LARGA ESCALA

SEBRAE/Nacional. Pesquisa Interna de Perfil do Curso Iniciando um Pequeno Grande Negócio. (2005)
Wickert, M. L. S. et al. Referencial para uma nova práxis educacional, Brasília: 2001. Edição SEBRAE.

\section{PALABRAS CLAVE}

E-learning, Tutoría, Acompanhamento.

\section{KEYWORDS}

E-learning, Tutory, Accompaniment.

\section{PERFIL ACADÊMICO DAS AUTORAS}

Giovana Schuelter, doutoranda e mestre em Mídia e Conhecimento pela Universidade Federal de Santa Catarina - UFSC e graduada em Ciência da Computação pela Universidade do Vale do Itajaí. Atua com desenvolvimento de conteúdo para cursos on-line no IEA. Atuou no desenvolvimento e acompanhamento de curso on-line no Instituto VIAS. Também como docente nas Faculdades Integradas Univest. Trabalhou com acompanhamento aos alunos de mestrado presencial/virtual de cursos à distância no LED- UFSC. E-mail: giovana@iea.org.br

Marcia Maria de Matos é Pós-graduada em Educação a Distância pela Universidade Católica de Brasília. Graduada em Comunicação Social pela Universidade Federal de Minas Gerais. Funcionária do SEBRAE há 18 anos, já exerceu a Gerência de Tecnologia da Informação, Coordenou projetos de Atendimento e Orientação Empresarial, atualmente coordena a execução dos cursos do SEBRAE pela Internet e atua diretamente em todos os projetos voltados para web. E-mail: marcia@sebrae. com.br

Mônica Guarezi Rodrigues é mestre em Mídia e Conhecimento pela Universidade Federal de Santa Catarina - UFSC e graduada em Matemática Licenciatura Plena com especialização em matemática do ensino médio. Tem como experência profissional: docência na educação básica e educação de jovens e adultos. Coordena a operacionalização dos cursos à distância e comunidades de prática do Instituto de Estudos Avançados. E-mail: monica@iea.org.br 
Sonia Grüdtner, Giovana Schuelter, Mónica Guarezi, Rita Menegaz y Marcia Matos ACOMPAHAMENTO AO ESTUDANTE A DISTANCIA: CURSO "INICIANDO UM PEQUEÑO GRANDE NEGOCIO- IPGN", UMA EXPERIENCIA DE CAPACITAÇAO EM LARGA ESCALA

Rita de Cássia Menegaz Guarezi é doutora em Mídia e Conhecimento pela Universidade Federal de Santa Catarina - UFSC e graduada em Pedagogia com especialização em metodologia do ensino e gestão de informática na educação. Tem como experiência profissional: docência na educação básica, ensino superior e pósgraduação. Coordena o Núcleo de Educação à Distância do Instituto de Estudos Avançados. E-mail: ritaguarezi@iea.org.br

Sônia Inez Grüdtner Floriano, doutoranda e mestre em Mídia e Conhecimento pela Universidade Federal de Santa Catarina - UFSC e graduada em Pedagogia também pela mesma Universidade. Coordena a operacionalização de cursos à distância no Instituto de Estudos Avançados. Atuou: como docente no Centro de Educação à Distância da Universidade do Estado de Santa Catarina; no acompanhamento aos alunos de Mestrado presencial/virtual e design pedagógico no Laboratório de Ensino à Distância da UFSC. E-mail: sonia@iea.org.br

$\begin{array}{ll}\text { Dirección Postal: } & \text { IEA - Instituto de Estudos Avançados } \\ & \text { Rodovia SC 401, } .^{\circ} \text { 6oo } \\ & \text { Centro de Tecnologia IlhaSoft - Conjunto 2C } \\ & \text { Bairro: João Paulo } \\ & \text { Cidade: Florianópolis - SC } \\ & \text { Estado: Santa Catarina } \\ & \text { Pais: Brasil } \\ & \text { CEP: 88030-0oo }\end{array}$

Fecha de entrega: 04.10.06

Fecha de aceptación: 23.12.06 